Citation: Federica Cisilino, Fabio A. Madau, Roberto Furesi, Pietro Pulina, BrunellaArru (2021) Organic and conventional grape growing in Italy: a technical efficiency comparison using a parametric approach. Wine Economics and Policy 10(2): 15-28. doi: 10.36253/wep10384

Copyright: (c) 2021 Federica Cisilino, Fabio A. Madau, Roberto Furesi, Pietro Pulina, Brunella Arru. This is an open access, peer-reviewed article published by Firenze University Press (http:// www.fupress.com/wep) and distributed under the terms of the Creative Commons Attribution License, which permits unrestricted use, distribution, and reproduction in any medium, provided the original author and source are credited.

Data Availability Statement: All relevant data are within the paper and its Supporting Information files.

Competing Interests: The Author(s) declare(s) no conflict of interest.

\section{Organic and conventional grape growing in Italy: a technical efficiency comparison using a parametric approach}

\author{
Federica Cisilino ${ }^{1}$, Fabio A. Madau $^{2, *}$, Roberto Furesi ${ }^{2}$, Pietro Pulina ${ }^{2}$, \\ Brunella Arru ${ }^{2}$ \\ ${ }^{1}$ CREA - Council for Agricultural Research and Economics - Research Centre for Agri- \\ cultural Policies and Bio-Economy c/o University of Udine, Via delle Scienze 206, 33100, \\ Udine (Italy).Email: federica.cisilino@crea.gov.it \\ ${ }^{2}$ Department of Agricultural Sciences - University of Sassari, Viale Italia 39/a, 07100 - \\ Sassari(Italy),Email: famadau@uniss.it; rfuresi@uniss.it; ppulina@uniss.it; brarru@ \\ uniss.it \\ ${ }^{\star}$ Corresponding author.
}

\begin{abstract}
Absract. Several studies have focused attention on the differences between organic and conventional farms in terms of efficiency, and controversial findings have resulted from these applications. One source of controversy concerns the assumption about the frontier(s) adopted for the comparison: a common frontier or two separate frontiers for organic and conventional methods? This paper aims to estimate technical efficiency in Italian grape farming. A stochastic frontier analysis (SFA) was applied to a sample of 531 farms (440 conventional and 91 organic farms) collected from the Farm Accountancy Network Database. Among others, a test for evaluating whether a unique or separate frontier was performed. The findings suggest that organic and conventional farms would lie on a common frontier and that organic farms have greater capacity than conventional farms in using their technical inputs (efficiency amounts to $83.6 \%$ and $77.8 \%$, respectively). Several implications derive from these findings.
\end{abstract}

Keywords: stochastic frontier analysis, technological homogeneity, inefficiency sources.

\section{INTRODUCTION}

Organic farming is a well-established reality in Europe, where it has been regulated since 1991. One of the most debated topics in this field consists of measuring organic and conventional agriculture's technical and economic performance [1] to highlight similarities and differences. Comparison between organic and conventional farming is a very interesting field of research where different approaches have been adopted to find out differences between the two systems mainly to compensate for organic farming additional costs and income foregone. The assumption is that the organic method discounts a gap on the production level compared to conventional agriculture $[2,3]$. 
This paper tries to give evidence of the effective differences in terms of technical efficiency in using inputs by farms as controversial findings have been found on this topic. The analysis is focused on the European grape-growing sector since the relevance of the organic wine sector and because the European Union (EU) accounts for $49 \%$ of the world grape-growing area [4]. Italy is the country that devotes the larger land in the world to organic grape-growing [5]. Specifically, Italian organic vineyards covered about $110 \mathrm{~K}$ hectares $(23 \%$ in conversion), corresponding to $15.5 \%$ of the total world organic vineyards area [4].

Estimating differences in grape-growing productivity is a crucial issue for better addressing policies and strategies in the sector. At the same time, assessing the role of efficiency in affecting production would provide useful information for understanding if the gap that organic grape-growing pays is only attributable to different productivity - therefore to the adoption of a less performing technology than the conventional one - or, vice versa, to another ability in using the inputs bundle.

This paper aims to provide a comparative analysis between Italian organic and conventional farms by estimating productivity and efficiency to confirm if a real difference in productivity exists and to evaluate the role of efficiency in affecting observed production level.

This paper also tackles the debate on the typology of frontiers that must be used to compare organic and conventional farms. The question turns on the consideration of organic and conventional orientation as two different techniques within a single technological horizon or, conversely, as two different technologies that, in turns, refer to two different types of agriculture that are not directly comparable. In this context, some conceptual and methodological problems arise and should be addressed: a) firstly, the risk is to consider systems that are not homogeneous from a technological or organisational point of view because organic farming is developed on well-defined production processes and use of technical inputs; b) secondly, conventional agriculture can be considered as a jumble of a plethora of agronomic techniques, some of them very close to the organic method, and it is difficult to trace back to a well-defined technical-production paradigm.

Regarding the latter aspect, conventional agriculture can be understood as the most widespread practice in each territory or, conversely, all alternative techniques to the organic method can be included in this category [6]. The answer to this question has pivotal implications. In the first case, due to the use of the same frontier for the two orientations and thus the possibility of directly comparing them, any different productivity levels are mainly determined by inefficiencies rather than by actual technological gaps. Conversely, the two measures are not comparable in the second case because of the difference in productivity derived from both inefficiencies and the different technology adopted by the two production orientations. This implies that the efficiency measure must be related to specific production frontiers, one for the organic method and one for the conventional one.

The remainder of this paper is organised as follows. Section 2 provides a review of the literature on efficiency estimation between organic and conventional agriculture and some information on the organic wine market. The research methodology and sample description are illustrated in Section 3. Section 4 shows the research results and discussion, and Section 5 concludes our paper, outlines the implications for practitioners, academics, and policymakers, and makes recommendations for future research.

\section{BACKGROUND}

Using an efficiency analysis, the manuscript aims to fill the gap in the current literature. In fact, although numerous studies have appeared on wine grape farms in other geographical contexts, these efficiency analyses have been applied without distinguishing between organic and conventional farming [7-12].

Concerning this sort of comparison research between organic and conventional wine grape farms, some controversial pieces of evidence have been provided by Bayramoglu and Gundogmus [13] on the Turkish sector, Tzouvelekas et al. [14] on Grecian farms, and Guesmi et al. [15] regarding Spain. Furthermore, Aldanondo-Ochoa et al. [16] analysed environmental and economic efficiency in the Spanish sector. Previous studies on organic farming have focused on the relationship between environment and competitiveness and the different use of resources between organic and conventional farms that green approaches could produce in terms of efficiency $[17,18]$.

Other scholars have put attention on the comparisons related to production practices, yields and economic performance $[2,3,19,20]$ or again on profitability [21]. Other recent studies have used meta-analysis to compare different countries' situations by implementing various methods and approaches, which gave evidence of the environmental and economic comparisons [22-25].

Still, some studies have assessed the agri-environmental schemes and organic measure impact of rural development policies [26-29]. Particular attention has been paid to estimating the technical and economic efficiency [30-34], and out of which conflicting results have 
emerged. On the one hand, studies focused on farm technical efficiency analysis - applying parametric or non-parametric techniques - have analysed both desirable and non-desirable outputs (ex. pollution) in different crop productions. These studies showed that it is not so evident that organic farms are less profitable and/or less efficient than conventional ones. Lansink et al. [35] compared crop and livestock farms in Finland, finding that organic crop is more efficient than conventional farming considering capital, land, labour, energy as inputs and the revenue as output. A study on the coffee sector in Nepal [36] found that organic farms are more efficient than conventional ones in terms of production, inter/ shade crops, considering farm size, capital, labour cost, fertiliser and plant protection as inputs.

Tzouvelakas et al. [37], analysing the olive sector in Greece applying a Stochastic Frontier Analysis (SFA), found that organic crop is more efficient than conventional farming. On the other hand, the Data Envelopment Analysis (DEA) technique applied on the studies of Damara et al. [38], Alkahtani and Elhendy [39], BeltránEsteve and Reig-Martínez [40], confirms the greater efficiency of conventional farms respectively as production, total revenue and sales are concerned.

In the same vein, Madau [34] and Serra and Goodwin [41], using the SFA to analyse the cereal sector in Italy and Spain, respectively, concluded that conventional farms are more efficient in terms of income and production terms. Kramol et al. [42] analysed the efficiency of vegetable farms in Thailand, considering the revenue as the output variable, finding that conventional farms are more efficient than organic ones. Tiedemann and Latacz-Lohmann [43] concluded the same for a group of arable farms in Germany. A two-stage DEA approach was performed to compare organic and conventional rain-fed cereals in Spain [44]. The results show that organic farms are more efficient in term of input consumption and GHG emissions.

A Local Maximum Likelihood (LML) approach was proposed by Guesmi et al. [15] to compare the efficiency levels of organic and conventional farms in Egypt. They found that results are slightly better for organic farms. Organic farms in Switzerland, Austria and Southern Germany were analysed by Lakner et al. [45] starting from the perspective of diversification and multifunctionality. They found that the benefits and drawbacks of diversification by applying a stochastic frontier combined with a metafrontier analysis estimating the effects on both productivity and efficiency.

Concerning the analysed sector, the wine market has traditionally represented an important and strategic segment of the EU agri-food system and, since the beginning of the EU Common Agricultural Policy (CAP), the wine sector policy has undoubtedly enjoyed a particular treatment [46-49].

Italy is the EU leader in terms of wine market $(47,5$ Mhl) - followed by France (42,1 Mhl) and Spain (33,5 Mhl) - and varieties included in the vineyard register (504), and production is well oriented to bulk wines and premium certified types, specifically PDO wines.

In this context, a remarkable role is played by organic production, which is constantly increasing in terms of the market and investments - this market is worth approximately 90 billion dollars worldwide [50] - and has highlighted growth that affects both demand and supply. Consumers look for healthy, environmentally friendly and safe wines, while producers aim at valid and marketable alternatives to conventional production to satisfy consumer demand [51-57].

Consumers with hedonistic and environmental protection values and beliefs would have a higher propensity to purchase organic wines $[58,59]$. Moreover, previous studies showed that the environmental benefits of organic wine production push consumers willing to pay more for it $[54,57,60]$. Fanasch and Frick [61] found that "organic practices are a credible signal for consumers, inducing them to pay a price premium" [61] (p. 20).

Concerning the organic certification, Abraben et al. [62] found that it exerts a positive effect on the price of low-quality rating wines, and this effect diminishes with increasing wine quality, till becoming penalising for higher quality wine. According to Ruggeri et al. [63], consumer attention and the WTP for certifications vanish when there are indications of the high quality of wine as the perception of high wine quality may generate less willingness to pay for more eco-certifications. Moreover, organic certification appears less important in the high-price segment than self-declaration [61]. Lim and Reed [64] research revealed a greater WTP for ecolabels of wines from less-prestigious regions rather than wines from higher-prestige regions, besides a greater WTP for organic wine than sustainable wines.

Preferences for organic wine are affected by sociodemographic and attitudinal variables [63]. Previous literature identifies the most frequent demographic characteristics of organic consumers: persons with higher incomes [e.g. 65-67], living in urban areas [e.g. 56,68], millennials and young adults [69,70] and women [e.g. 55,56,67]. But also the frequency of consumption [66], wine education [63] and knowledge degree of the labels [63,71].

Therefore, as eco-labelled products, organic wines allow wine producers to sell products with higher added value than conventional wines and will enable them to stay competitive in an increasingly globalised market. 


\section{MATERIALS AND METHODS}

Technical efficiency (TE) is defined as the measure of the ability of a firm to obtain the best production from a given set of inputs (output-increasing oriented) or, vice versa, as the measure of the ability to use the minimum feasible amount of inputs given a level of output (input-saving oriented) [72,73]. In these terms, technical inefficiency is defined as the degree to which firms fail to reach optimal production.

Different methods have been proposed in the literature to estimate TE and its related measures. In this study, a stochastic frontier analysis (SFA) approach was adopted. A parametric approach was preferred to the non-parametric approach because of three inherent abilities: first, the possibility of including in a unique model the production frontier and the inefficiency models; second, the ability to estimate the input elasticities directly; and third, the possibility of testing the more appropriate function that describes the production process.

In the SFA model, the production frontier is specified, defining output as a stochastic function of a given bundle of inputs. This approach means that the error term e may be separated into two terms: a random error and a random variable explanatory of inefficiency effects as follows.

$y_{i}=f\left(x_{i}, \beta\right) \bullet \exp (\varepsilon)$ and $\varepsilon=\left(v_{i}-u_{i}\right) \quad i=1,2, \ldots N$

Where $y_{i}$ denotes the level of output for the $i$-th observation; $x_{i}$ is the row vector of inputs; $\beta$ is the vector of parameters to be estimated; $f($.$) is a suitable function-$ al form for the frontier; $v_{i}$ is a symmetric random error assumed to account for measurement errors and other factors not under the control of the firm; and $u_{i}$ is an asymmetric nonnegative error term assumed to account for technical inefficiency in production. The MLE (maximum likelihood estimation) of (1) allows us to estimate the vector $\beta$ and the variance parameters $\sigma^{2}=\sigma^{2}{ }_{u}+\sigma^{2}{ }_{v}$ and $\gamma=\sigma_{u} / \sigma_{v}$; where $g$ varies between 0 and 1 .

Consequently, $\mathrm{TE}_{i}=\exp \left(-u_{i}\right)$, and the frontier production is calculated as its observed production divided by its $\mathrm{TE}_{i}$ value.

Some authors have proposed a one-stage method that permits contextual estimation of the inefficiency effects caused by factors that affect efficiency, assuming that inefficiency effects $\left(u_{i}\right)$ are expressed as a function of a vector of observable explanatory variables . Specifically, Battese and Coelli (1995) adapted these models and proposed an approach where the inefficiency term $u_{i}$ has a truncated (at zero) normal distribution with mean $m_{i}$ :
$u_{i}=m_{i}+W_{i}$ and $m_{i}=\mathbf{Z}\left(z_{i}, \delta\right) \quad i=1,2, \ldots N$

Where $W_{i}$ is a random error term that is assumed to be independently distributed, with a truncated $\left(\right.$ at $\left.-m_{i}\right)$ normal distribution with mean zero and variance $\sigma^{2}$; $\mathbf{Z}$ is the vector $(\mathrm{Mx} 1)$ of the $z_{i}$ firm-specific variables of inefficiency; and $d$ is the $(1 \mathrm{xM})$ vector of unknown coefficients associated with $z_{i}$. In this way, we can estimate inefficiency effects arising from the $z_{i}$ explanatory variables.

The model adopted by Battese and Coelli [77] was used in this study.

\section{Data description}

The information used was collected from cross-sectional data of Italian specialised grape-growing farms. Specifically, we analysed 531 farms that participated in the official Farm Accountancy Data Network (FADN) during 2017.

The dataset consists of 440 conventional and 91 organic farms. All the selected organic farms were in the maintenance phase. However, we excluded farms with less than 40K Euros of Gross Farm Revenue (GFR) from the sample to limit the risk of considering too small and not very market-oriented activities.

A summary description of the sample is reported in Table 1.

It must be emphasised that farms were included with different inputs and capital endowments. The choice depends on the need for estimating the possible difference in productivity in the sample and, more precisely, whether switching from conventional to organic in Italian grape growing affects productivity. In other words, we estimated if conventional and organic farms lie on the same technologic horizon, or vice versa, they separately describe two production functions, each one characterised by a given level of productivity. For this reason and contrary to other studies [e.g. 34], we did not select two homogeneous subsamples of farms.

For the same reason, we included both farms that produce grapes for processing PDO and GPI wine and farms that produce other wines. Indeed, analytically, we estimated whether quality orientation affects productivity or, more generally, if all farms lie or not on the same technological horizon.

Table 1 shows that, on average, organic farms appear more productive than conventional farms. However, an empirical test would suggest whether this represents a discriminating factor for considering conventional and organic as two different agricultural methods in Italian grape growing. 
Table 1. Summary statistics of the collected sample.

\begin{tabular}{|c|c|c|c|c|c|c|}
\hline \multirow[b]{2}{*}{ Variable } & \multicolumn{2}{|c|}{ Conventional } & \multicolumn{2}{|c|}{ Organic } & \multicolumn{2}{|c|}{ Total } \\
\hline & Mean & s.d & Mean & s.d & Mean & s.d \\
\hline Value of production (Euros) & 196,634 & 420,374 & 240,784 & 378,282 & 204,200 & 413,461 \\
\hline Land area (hectares) & 18.8 & 26.0 & 32.8 & 39.4 & 21.2 & 29.1 \\
\hline Labour (working units) & 2.5 & 3.2 & 3.3 & 3.2 & 2.6 & 3.2 \\
\hline Annual capital depreciation (Euros) & 13,552 & 20,549 & 22,505 & 45,769 & 15,086 & 26,775 \\
\hline Variable costs (Euros) & 62,166 & 184,542 & 79,642 & 147,163 & 65,161 & 178,688 \\
\hline \multicolumn{7}{|l|}{ PDO and GPI (\% of farms) } \\
\hline Oriented & 82.4 & & 85.0 & & 84.6 & \\
\hline No oriented & 17.6 & & 15.0 & & 15.4 & \\
\hline \multicolumn{7}{|l|}{ Management (\% of farms) } \\
\hline Only or mostly family workers & 86.2 & & 60.3 & & 82.2 & \\
\hline Only or mostly wage workers & 13.8 & & 39.7 & & 17.8 & \\
\hline \multicolumn{7}{|l|}{ Gender of farmer (\% of farms) } \\
\hline Male & 81.8 & & 74.7 & & 80.6 & \\
\hline Female & 18.2 & & 25.3 & & 19.4 & \\
\hline Age of farmer (\% of under 40$)$ & 11.4 & & 9.9 & & 11.1 & \\
\hline \multicolumn{7}{|l|}{ Region (\% of farms) } \\
\hline Northern Italy & 60.7 & & 28.6 & & 55.2 & \\
\hline Central Italy & 28.4 & & 35.1 & & 29.6 & \\
\hline Southern Italy & 10.9 & & 36.3 & & 15.2 & \\
\hline
\end{tabular}

Source: Authors' data processing on FADN data.

\section{The functional model}

A translog functional form was assumed as the frontier technology specification for the farms. Using the Battese and Coelli [77] procedure, the translog function is specified as follows.

$\ln Y_{i}+\beta_{0}+\sum_{j=1}^{4} \ln x_{j i}+1 / 2 \sum_{j \leq}^{4} \sum_{K=1}^{4} \beta_{j k} \ln x_{k i}{ }^{*} \ln x_{k i}+$ $S_{m}+S_{q}+R_{n}+R_{c}+R_{s}+A_{m}+A_{h}+A_{p}+\left(v_{i}-u_{i}\right)$

Where the subscript $i=1,2 \ldots N$ denotes the observation for the $i$-th firm and $j, k=1,2 \ldots J$ stand for the technical inputs used. The dependent variable $(Y)$ represents the value (in Euros) of production and corresponds to the GFR. The bundle of inputs is composed by

$X_{1}$ is the total land area (expressed in UAA hectares) devoted to grapes by each farm;

$X_{2}$ is the total amount of labour (expressed in working units);

$X_{3}$ is the cost (Euros) of capital in terms of annual depreciation;

$X_{4}$ represents the other variable costs (Euros) supported by each farm.
Furthermore, we included other dummy variables that can affect grape-growing productivity and, as a consequence, determine the technological differences among farms.

First, the model involves a dummy variable $\left(\mathrm{S}_{\mathrm{m}}\right)$ that considers the agronomic method practised (organic cultivation $=1$; conventional cultivation $=0$ ). The inclusion of a given variable permits us to estimate whether technological homogeneity exists between organic and conventional grape growing. In this sense, a unique technological frontier for both organic and conventional farms was assumed. The variable's eventual estimated significant effect would suggest refereeing the analysis on separate frontiers (nontechnological homogeneity). In one case (unique frontier), possible differences in estimated efficiency by the two groups would be solely related to different abilities in using technical factors available to the farmer; in the other case (separate frontiers), efficiencies cannot directly be compared because a difference in productivity also exists.

Second, a variable $\left(\mathrm{S}_{\mathrm{q}}\right)$ that takes into account farm orientation towards the production of PDO and GPI wines was included (farms that grow grapes for PDO 
and GPI wines $=1$; any orientation $=0$ ). According to this distinction, we would understand if orientation to this well-defined quality standard plays a role in conditioning productivity and efficiency, living aside the cultivation method (conventional or organic).

Finally, three dummies $(0=$ No; Yes $=1)$ reflecting the geographical location of the farms (Northern $R_{n}$, Central $R_{c}$, and South $R_{s}$ Italy) and three other variables corresponding to altimetry (Mountain $A_{m}$, Hilly $A_{h}$, and Plane $A_{p}$ ) were introduced in the model.

Concerning the inefficiency effects, the model has the following form:

$u_{i t}=\delta_{0}+\delta_{1} Z_{i 1}+\delta_{2} Z_{i 2}+\delta_{3} Z_{i 3}+\delta_{4} \mathrm{~S}_{\mathrm{m}}+\delta_{5} \mathrm{~S}_{\mathrm{q}}+\delta_{6}$

$\mathrm{R}_{\mathrm{n}}+\delta_{7} \mathrm{R}_{\mathrm{c}}+\delta_{8} \mathrm{R}_{\mathrm{s}}+\delta_{9} \mathrm{~A}_{\mathrm{m}}+\delta_{10} \mathrm{~A}_{\mathrm{h}}+\delta_{11} \mathrm{~A}_{\mathrm{p}}+W_{i}$

Where $Z_{1}$ represents the type of farm management (only or mostly family workers $=0$; only or mostly wage workers $=1) ; Z_{2}$ represents the gender of the farmer (male $=1$; female $=2)$; and $Z_{3}$ represents the age of the farmer.

The other variables are identified with the same dummies that appeared in the function model, whereas $W_{i}$ is the error term.

\section{RESULTS AND DISCUSSION}

The production function and inefficiency parameters were estimated simultaneously using the computer program FRONTIER@ 4.1, created by Coelli [78].

\section{The preferable efficiency model}

A set of tests was applied to evaluate the suitability and significance of the adopted model concerning the data. All tests were carried out by the generalised likelihood-ratio test procedure, which permits evaluating a restricted model with respect to the adopted model [79]. The statistic associated with this test is defined as follows:

$\left.l=-2 \ln \Lambda=-2\left[\ln \frac{\mathrm{L}\left(H_{0}\right)}{\mathrm{L}\left(H_{1}\right)}\right]=-2 \ln \mathrm{L}\left(H_{0}\right)-\ln \mathrm{L}\left(H_{1}\right)\right]$

Where $\mathrm{L}(\mathrm{H} 1)$ and $\mathrm{L}(\mathrm{H} 0)$ are the log-likelihood values of the adopted model and the restricted model, respectively. The statistical test $\lambda$ has approximately a chi-square or a mixed-square distribution with several degrees of freedom equal to the number of parameters (restrictions) assumed to be zero in the $\mathrm{L}(\mathrm{H} 0)$ null hypothesis. If the value of $\lambda$ is lower than the corresponding critical value (for $\alpha=0.05$ significance level), the null hypothesis cannot be rejected, and therefore, the preferred model would avoid these variables.

The first test concerned the functional form of the function. The starting (null) hypothesis (Cobb-Douglas; $\beta_{i j}=0$ ) was compared with the adopted hypothesis (Translog). The null hypothesis was not rejected, implying that Cobb-Douglas can be a good representation of the data.

The second test concerned the hypothesis of technological homogeneity between organic and conventional grape growing. The starting hypothesis implies that the two methods are homogenous bundles of a defined technology $\left(S_{m}=0\right)$, and it was compared with the adopted hypothesis of nontechnological homogeneity between the two methods $\left(\mathrm{S}_{m}{ }^{1} 0\right)$. The null hypothesis was not rejected. Therefore, the variable can be avoided in the preferred model, and as a consequence, organic and conventional grape-growing farms lie on a unique production frontier.

The third test concerned the comparison between the null hypothesis of invariance with respect to quality orientation $\left(\mathrm{S}_{\mathrm{q}}=0\right)$ and the hypothesis of variance $\left(\mathrm{S}_{q}{ }^{1} 0\right)$ a priori adopted. We found that the null hypothesis could not be rejected; hence, the preferred model is invariant to quality orientation.

The fourth and fifth tests were applied to the hypotheses about the role of geographical location ( $R$ variables) and altimetry (A variable) in conditioning productivity, respectively. Additionally, in these cases, the results from the two tests suggest that geographical location and altimetry would not be significant factors in describing the technology, and a common frontier can be adopted in the preferred model (without these variables).

All the estimated results of the tests on the production frontier are reported in Table 2.

The model was re-estimated considering these findings, and the following tests of the inefficiency model were applied to the re-estimated Cobb-Douglas model:

- if inefficiency effects $\left(\gamma ; \delta_{0 ;} \delta_{1} \ldots \delta_{3}\right)$ are present in the model;

- the stochastic nature of the inefficiency effects (presence of $\gamma$ and $\delta_{0}$ );

- the presence of the intercept $\left(\delta_{0}\right)$;

- if the firm-specific factors $\left(\delta_{1 . . .} \delta_{3}\right)$ are present;

- if the $S_{m}$ and $S_{q}$ variables significantly affect inefficiency;

- if the geographical location significantly affects inefficiency;

- if altimetry significantly affects inefficiency;

- if each firm-specific factor is present.

The results suggest that all the null hypotheses could 
Table 2. Tests of hypotheses for the frontier function and inefficiency model parameters.

\begin{tabular}{|c|c|c|c|c|c|c|}
\hline Restrictions & Model & $\mathrm{L}\left(\mathrm{H}_{0}\right)$ & $\lambda$ & d.f. & $\chi_{0.95}^{2}$ & Decision \\
\hline \multicolumn{7}{|l|}{ Production Function } \\
\hline None & Translog & -97.08 & & & & \\
\hline$H_{0}: b_{i j}=0$ & Cobb-Douglas & -104.71 & 15.26 & 10 & 18.31 & Not rejected \\
\hline$H_{0}: \mathrm{S}_{m}=0$ & Conventional vs. organic & -97.98 & 1.80 & 1 & 3.84 & Not rejected \\
\hline$H_{0}: \mathrm{S}_{q}=0$ & PDO vs. No PDO & -98.33 & 2.50 & 1 & 3.84 & Not rejected \\
\hline$H_{0}: \mathrm{R}_{n}, \mathrm{R}_{c}, \mathrm{R}_{s}=0$ & Geographical location & -99.05 & 3.94 & 3 & 7.82 & Not rejected \\
\hline$H_{0}: \mathrm{A}_{m}, \mathrm{~A}_{c}, \mathrm{~A}_{p}=0$ & Altimetry & -99.41 & 4.66 & 3 & 7.82 & Not rejected \\
\hline \multicolumn{7}{|l|}{ Inefficiency model } \\
\hline None & Cobb-Douglas & -105.44 & & & & \\
\hline$H_{0}: g=d_{0} ; d_{1} \ldots d_{3}=0$ & No inefficiency effects & -112.55 & 14.22 & 4 & $8,76^{*}$ & Rejected \\
\hline$H_{0}: g=d_{0}=0$ & No stochastic effects & -109.01 & 7.14 & 2 & $5.14^{\star}$ & Rejected \\
\hline$H_{0}: d_{0}=0$ & No intercept & -107.88 & 4.88 & 1 & 3.84 & Rejected \\
\hline$H_{0}: d_{1} \ldots d_{3}=0$ & No firm-specific factors & -110.41 & 9.94 & 3 & 7.82 & Rejected \\
\hline$H_{0}: \mathrm{S}_{m}=0$ & No conv vs. org. & -108.82 & 6.76 & 1 & 3.84 & Rejected \\
\hline$H_{0}: \mathrm{S}_{q}=0$ & No quality & -110.11 & 9.34 & 1 & 3.84 & Rejected \\
\hline$H_{0}: \mathrm{R}_{n}, \mathrm{R}_{c}, \mathrm{R}_{s}=0$ & No geograph. location & -108.73 & 6.58 & 3 & 7.82 & Not rejected \\
\hline$H_{0}: \mathrm{A}_{m}, \mathrm{~A}_{c}, \mathrm{~A}_{p}=0$ & No altimetry & -108.90 & 6.92 & 3 & 7.82 & Not rejected \\
\hline$H_{0}: Z_{1}=0$ & No management & -108.05 & 5.22 & 1 & 3.84 & Rejected \\
\hline$H_{0}: Z_{2}=0$ & No age & -107.99 & 5.10 & 1 & 3.84 & Rejected \\
\hline$H_{0}: Z_{3}=0$ & No gender & -108.90 & 6.92 & 1 & 3.84 & \\
\hline
\end{tabular}

* The statistic 1 for these variables is distributed as a mixed $c^{2}$ because the tests involve equality and inequality restrictions. The relative upper bounds are shown in Table 1 in Kodde and Palm [80].

Source: Authors' analysis of FADN data.

be rejected except for the geographical location and altimetry variables that hence can be excluded by the final model. The estimated parameters of the preferred model are reported in Table 3.

\section{The production function}

Each parameter related to the function model satisfies the monotonicity and diminishing marginal productivity properties at the point of approximation (positive signs), and it can be taken as an elasticity indicator. This finding means that capital would contribute the most to grape production in the Italian sector (0.585). Labour was estimated as the second most influential factor (0.371), whereas variable costs (0.121) and land area (0.085) appear to affect productivity weakly. Specifically, to the latter input, the low elasticity might depend on the fact that grapes are typically grown in an intensive or semi-intensive way in the case of scarce land availability. In this sense, the land is a factor that affects production, but as estimated, it plays no relevant role in conditioning productivity.

For this reason, the low amount of land contrasts with what was found in other wine grape-growing realities, where this factor was estimated to be among the factors most affecting efficiency $[7,12]$ or in other efficiency studies carried out on (more extensive) small farms [81].

Returns to scale - calculated summarising the single input elasticities - are generally increasing (1.162), implying that margins exist (approximately 16\%) for improving the scale inefficiency of the grape-growing farms to increase the returns to scale.

Similar findings have been found in other studies on the wine grape-growing sector. Regarding the South African sector, for example, Townsend et al. [82] and Conradie et al. [7] estimated that farms are too small and prevalently operate on returns to scale conditions. On the other hand, Liu and Lv [83], in a study on Chinese wine grape farms, found that medium farms reveal a higher efficiency than smaller and larger farms. 
Table 3. ML Estimates for SFP parameters for the organic and conventional data - preferred model.

\begin{tabular}{lccc}
\hline Variable & Parameter & Coeff. & S.e. \\
\hline Frontier ModeL & & & \\
Constant & $\mathrm{b}_{0}$ & 0.818 & 0.105 \\
Land area & $\mathrm{b}_{1}$ & 0.085 & 0.222 \\
Labour & $\mathrm{b}_{2}$ & 0.371 & 0.219 \\
Capital & $\mathrm{b}_{3}$ & 0.585 & 0.280 \\
Other expenditures (variable costs) & $\mathrm{b}_{4}$ & 0.121 & 0.050 \\
\hline Inefficiency Model & & & \\
Constant & $\mathrm{Z}_{0}$ & -0.003 & 0.018 \\
Management & $\mathrm{Z}_{1}$ & 0.142 & 0.186 \\
Gender & $\mathrm{Z}_{2}$ & -0.051 & 0.100 \\
Age & $\mathrm{Z}_{3}$ & 0.059 & 0.136 \\
Organic & $\mathrm{S}_{\mathrm{m}}$ & -0.185 & 0.115 \\
Quality & $\mathrm{S}_{\mathrm{q}}$ & -0.126 & 0.156 \\
\hline
\end{tabular}

Variance parameters

\begin{tabular}{cccc} 
& $\sigma^{2}$ & 0.277 & 0.133 \\
& $g$ & 0.042 & 0.026 \\
& $\mathrm{~g}^{*}$ & 0.467 & \\
Log-likelihood function & & -106.386 & \\
\hline
\end{tabular}

Source: Authors' data processing on FADN data.

Research findings from Carvalho [8], Moreira [9], and Coelli and Sanders [10] on the Portuguese, Chilean, and Australian sectors, respectively, reveal that returns to scale are close to unity.

\section{The inefficiency model}

Table 3 also reports the estimated parameters related to the inefficiency model. The findings suggest that efficiency tends to increase in the case of farms managed by young farmers (the positive sign associated with the variable Age indicates that it positively affects inefficiency) and by males (vice versa, the negative sign of the variable Gender means that efficiency would increase with the increase in the variable).

We also found that capitalistic farms tend to be less efficient than (solely or prevalently) family-run businesses. This last finding is only apparently surprising because it is probably related to the general intensive or semiintensive grape cultivation in Italy, living aside from the management. Furthermore, family-run farms are likely to be more cautious in using their inputs to compensate for the productivity gap, which could be a reason that may help explain this finding.

Furthermore, organic and quality-oriented farms tend to be more efficient than conventional and nonoriented farms, respectively. Specifically, the parameter associated with the organic/conventional dichotomy shows the highest magnitude, implying that it is the variable that mostly affects efficiency among the selected dichotomies.

\section{The technical efficiency}

The estimated technical efficiency of the sample amounts, on average, to 0.788 (Table 4). This means that room for improvement of approximately $21 \%$ exists for increasing the ability of Italian grape-growing farmers to use their technical inputs more efficiently.

The value is very close to the mean technical efficiency estimated by Carvalho [8] on Portuguese wine grape farms in 2000 (0.793), even if this value tends to decrease over time. Additionally, Moreira et al. [9] and Coelli and Sanders [10] estimated similar scores on wine grape farms (0.778 and 0.790 , respectively).

However, as expected in light of the estimated inefficiency parameters, the organic farms reveal a greater technical efficiency than the conventional farms. Since these scores refer to a unique frontier and the difference appears significant (for $\alpha=0.01$ ), it is possible to argue that organic farms have greater capacity than conventional units in using technical inputs (in the availability of the farmer). Since technical efficiency scores are calculated as an output-oriented measure in this study, the results imply that both farming methods might increase production using the same input bundle.

Organic and conventional grape-growing farmers would be able to increase output by $16.5 \%$ and $22.2 \%$, respectively, with the present state of technology and using their disposable resources more efficiently.

These findings confirm previous studies. In a study on Greek organic and conventional wine grape farms, Tzouvelekas et al. [84] found that organic farms show

Table 4. Estimated technical efficiency scores.

\begin{tabular}{lll}
\hline & Mean & s.d. \\
\hline Total sample (n. 531) & 0.788 & 0.108 \\
Organic (n. 91) & 0.835 & 0.102 \\
Conventional (n. 440) & 0.778 & 0.107 \\
\hline
\end{tabular}

${ }^{*} p$-values for t-tests on the mean difference between the two subsamples: $\mathrm{TE}=1.33 \times 10^{-4}$. 
higher efficiency than conventional farms $(0.680$ and 0.612 , respectively). In the Spanish sector, Guesmi et al. [15] estimated a greater difference between the two categories ( 0.796 and 0.642 , respectively). Aldanondo-ochoa et al. [16], comparing the total farm revenues of wine grape producers using inputs, such as land, labour and other costs, and assessing the environmental impact, found a higher efficiency for organic farms.

Conversely, the results from Bayramoglu and Gundogmus [13] on Turkish farms suggest that conventional grape farms are more efficient than organic farms. However, these scores refer to two separate frontiers; therefore, our findings are not comparable to those of this previous study.

Considering the observed GFR, it means that the achievement of full efficiency would lead to income increases of $47.6 \mathrm{M} €$ and $55.3 \mathrm{M} €$ for organic and conventional farms, respectively. Therefore, conventional farms could partially fill the revenue gap concerning organic farms in the case of full efficiency.

An important point is to assess the weight of inefficiency in affecting production to evaluate whether a possible improvement in efficiency could significantly affect productivity in grape-growing farms. Analysis of the ratio parameter $g$ provides information on the TE relevance for the production process.

The estimated $g$ is significant at the $1 \%$ level, which indicates that TE is relevant in explaining output variability. On the other hand, the parameter value could not be taken as a measure of the relative contribution of the inefficiency term to the total output variance. However, this measure can be obtained by estimating parameter $\gamma^{*}$, calculated as described in Table 3 . The estimation suggests that $46.7 \%$ of the general differential between observed and best-practice output is due to farmers' existing difference in efficiency.

This study highlights some pieces of evidence in the management of organic and conventional grape farming in Italy. The results suggest that organic and conventional farming systems would lie on a common frontier and that those organic farms seem more careful in using factors of production factors (technical inputs). This factor would be partly due to their awareness of the existing gap in terms of yields compared to conventional farms, which would also represent a general behaviour of organic producers who are constantly looking for greater performance.

\section{Pricing and output value}

As far as the output is concerned, it has to be considered that the production data estimation has been carried out in terms of farms' production value. Since the output is higher for organic farms (compared to conventional farms), our findings show that in the wine grape-growing sector, organic farms are more technically efficient than conventional farms. This point requires some further comment.

First, it is worth noting that the higher selling prices that organic farms can manage to command for their products play a role in the organic and conventional farming match. It must be said in fairness that the value of the grapes is substantially different, depending on their quality and typology [85]. Moreover, it is also true that the price of grapes varies according to many characteristics, such as the land on which the vineyards are grown, the costs of cultivation, the environmental conditions and any legislative decisions $[86,87]$. The main distinction is to be made between DOP wine grapes (more expensive) and table grapes. We find different varietals with different prices within the two types, depending on the yields and the wine qualities they could express.

In Italy, common criteria and specific associations are generally used to establish the prices of wine grapes, sometimes private and sometimes governmental. The latter annually provides the grape prices in agreement with the Chambers of Commerce. Then, there are private agreements between high-quality companies and winegrowers. Differences are both dependent on whether the wine producer is also a grape grower or not and the owner or not of the vineyards. When the wine market is rising sharply, the large brand wine producers could find it difficult to meet their needs with their vineyards (sometimes they cannot cover all the production in terms of grape quantities), and therefore they must go to the grape market.

These companies consistently turn to the same trusted growers, entering into multi-year contracts. Any DOP wine producer uses this strategy and pays different prices, depending on the area of origin. When producing high-quality wine, it is essential to establish a lasting relationship of trust and collaboration to obtain the best results. Prices can vary by a wide range, mainly depending on the quality, type (red or white), grape varietal and other factors, ranging from 20 Euros to more than 200 Euros per quintal for some special wines [88].

We should also not forget that sustainable and environmentally friendly practices, as known, require higher costs and higher prices for the final products (to compensate). Suffice it to say that among other rules, the EU normative, for example, states that to obtain authorisation for organic wine, producers must include a maximum sulphite content (set at $100 \mathrm{mg}$ per litre for red wine and $150 \mathrm{mg} / \mathrm{L}$ for white/rosé). The premium price 
should compensate for the higher costs for organic wine production. Today, the price of organic grapes in Italy is, on average, approximately $2,20 € / \mathrm{kg}$ [89].

Second, comparing prices, another point to be considered is producers' ability to promote and communicate the product's characteristics. In the recent past, in many Italian regions, organic grapes were sold as highquality grapes, but the added value of being organic was not valued [90]. In recent years, the scenario has changed since increasing attention has been given to sustainability and climate change issues [91]. In this evolving context, grape producers have become more aware of the importance of communicating the agricultural methods adopted to respect both the territory and human health. In effect, "consumers seem more interested in environmental aspects associated with organic production, that have more direct benefits on health than other environmental issues [and their] perception of sustainable wines seems generally associated with the terms such as organic and local" [92].

In this scenario, since a higher quality is traditionally attributed to sustainable wine, its communication to consumers through recognisable signs appears to be a very important marketing and competitive factor for wine producers $[92,93]$. In this respect, the Regulation of the European Commission [49], which defines and regulates organic wine production, allows farmers that respect these rules to boast the EU certification of "organic".

Finally, it must be underlined that a time lag would exist between when grapes are paid to produce wines and when wines are sold because wine generally takes several years to become market-ready. It means that the premium price applied by organic wine producers to grape-growers would reflect future wine price expectations, and it can be a source of distortion along with the price transmission from buyers to farmers.

\section{CONCLUSIONS}

With a specific application to grape growth, this study contributes to the debate on the efficiency and productivity of organic and conventional farming, which has produced controversial evidence throughout the world; however, it requires many more studies on the wine grape-growing sector.

As far as the farm's efficiency is concerned, it turns out that being organic and quality-oriented are characteristics that lead to a more efficient system.

Because grape-growing managed by young male farmers shows a higher efficiency level, the policymaker should encourage new farms' opening by young entrepreneurs and the generational shift even more. Moreover, the lower efficiency of companies run by women implies that there is an increasing need to provide more training and tools to support female entrepreneurs. A significant point concerns the variable of business-conducting typology. The higher level of efficiency of grapegrowing conducting family-run businesses must push policymakers increasingly to support these activities. Using their production inputs more carefully to respond to the need for an ever-decreasing use of resources, family farms appear to be crucial agents in achieving sustainable development goals.

Concerning the two production orientations, the findings show that capital and labour are the two key issues that contribute the most to grape production in Italy, confirming previous studies in the Spanish sector [94]. Moreover, this study disavows previous studies that see land as one of the most important factors affecting the efficiency of wine grape growth $[7,12]$.

Another noteworthy item is the positioning of the two production orientations along the same technological horizon due to the lack of a significant difference in productivity between organic and conventional wine grape farms. This aspect is relevant for those companies that, looking at the trend of organic wine and sparkling wine $(+15.5 \%$ variation between $2020 / 2019)$ compared to non-organic products $(+4 \%)$ [5] but also in light of the "Farm to Fork" strategy [95] aim to accelerate our transition to a sustainable food system also through the increase of up to $25 \%$ by 2030 of the area cultivated organically, intending to convert their production.

This finding is also relevant for academics, who, despite the increasing number of studies that compare the performance of organic and conventional agriculture in terms of yield, environmental, and economic impacts, still quote methodological difficulties of comparing conventional and organic systems [1].

This paper has some limitations. The focus is on only one country (Italy). Further multi-country research could be useful to confirm our findings in other fields, and more research needs to be done, also concerning our case (i.e., estimation of scale efficiency and the role of price in affecting productivity), to obtain more evidence on this issue. However, more research needs to be done to improve the quality of information about differences in efficiency between organic and conventional farming, especially in the wine grape-growing sector. 


\section{REFERENCES}

[1] A. Le Campion, F.-X. Oury, E. Heumez, B. Rolland, 2020. Conventional versus organic farming systems: dissecting comparisons to improve cereal organic breeding strategies. Org. Agric. 10, 63-74.

[2] N.H. Lampkin, 1994. Researching organic farming systems, in: The Economics of Organic Farming: An International Perspective. Cab International Wallingford, 343-359.

[3] F. Offermann, N. Lampkin, 2005. Organic farming in FADNs-comparison issues and analysis. Eur. Framew. Org. Mark. Inf. 107, 106.

[4] OIV, 2020. Nota di congiuntura del settore vitivinicolo mondiale nel 2019.

[5] SINAB, 2020. Bio in cifre 2020.

[6] F. Offermann, H. Nieberg, 2000. Economic performance of organic farms in Europe, Economics and Policy. Universität Hohenheim, Hohenheim.

[7] B. Conradie, G. Cookson, C. Thirtle, 2006. Farm size in Western Cape grape production: An enquiry into pooling small datasets. South Afr. J. Econ. 74, 334-343.

[8] M. Carvalho, P. Henrique, F. Costa, R. Pereira, 2008. Characterization and technical efficiency of Portuguese wine farms, in: Proceedings of the XIIth Congress of the EAAE. Ghent, Belgium.

[9] V.H. Moreira, J.L. Troncoso, B.E. Bravo-Ureta, 2011. Technical efficiency for a sample of Chilean wine grape producers: A stochastic production frontier analysis. Int. J. Agric. Nat. Resour. 38, 321329.

[10] T. Coelli, O. Sanders, 2013. The technical efficiency of wine grape growers in the Murray-Darling Basin in Australia, in: Wine Economics: Quantitative Studies and Empirical Applications. Palgrave Macmillan, Basingstoke, United Kingdom, 231-249.

[11] J. Lwelamira, P. Wambura, J. Safari, 2015. Technical efficiency in grape farming among smallholder farmers in Dodama urban districh, central Tanzania. Rural Plan. J. 17, 1-16.

[12] J. Piesse, B. Conradie, C. Thirtle, N. Vink, 2018. Efficiency in wine grape production: comparing long-established and newly developed regions of South Africa. Agric. Econ. 49, 203-212.

[13] Z. Bayramoglu, E. Gundogmus, 2008. Cost efficiency on organic farming: a comparison between organic and conventional raisin-producing households in Turkey. Span. J. Agric. Res. 6, 3-11.

[14] V. Tzouvelekas, C.J. Pantzios, C. Fotopoulos, 2002. Measuring multiple and single factor technical efficiency in organic farming. Br. Food J.
[15] B. Guesmi, T. Serra, Z. Kallas, J.M.G. Roig, 2012. The productive efficiency of organic farming: the case of grape sector in Catalonia. Span. J. Agric. Res. 552-566.

[16] A.M. Aldanondo-Ochoa, V.L. Casasnovas-Oliva, A. Arandia-Miura, 2014. Environmental efficiency and the impact of regulation in dryland organic vine production. Land Use Policy 36, 275-284.

[17] M.E. Porter, C. Van der Linde, 1995. Toward a new conception of the environment-competitiveness relationship. J. Econ. Perspect. 9, 97-118.

[18] S. Ambec, P. Lanoie, 2008. Does it pay to be green? A systematic overview. Acad. Manag. Perspect. 45-62.

[19] H. Nieberg, F. Offermann, 2000. Economic performance of organic farms in Europe. Universität Hohenheim, Stuttgart-Hohenheim.

[20] F. Offermann, 2004. Comparing organic and conventional farm incomes in FADN: Issues in international harmonisation and quality assurance. Presented at the Development of a European information system for organic markets-improving the scope and quality of statistical data: Proceedings of the 1st EISFOM European Seminar. Frick: FiBL, 115-118.

[21] H. Nieberg, F. Offermann, 2003. The profitability of organic farming in Europe. Organic agriculture: sustainability, markets and polices. Organic agriculture: sustainability, markets and polices. OECD workshop on organic agriculture, Washington, UK, USA.

[22] K. Mondelaers, J. Aertsens, G. Van Huylenbroeck, 2009. A meta-analysis of the differences in environmental impacts between organic and conventional farming. Br. Food J. 111, 1098-1119.

[23] D. Pimentel, P. Hepperly, J. Hanson, D. Douds, R. Seidel, 2005. Environmental, energetic, and economic comparisons of organic and conventional farming systems. BioScience 55, 573-582.

[24] H.L. Tuomisto, I. Hodge, P. Riordan, D.W. Macdonald, 2012. Does organic farming reduce environmental impacts?-A meta-analysis of European research. J. Environ. Manage. 112, 309-320.

[25] S. Uthes, B. Matzdorf, 2013. Studies on agri-environmental measures: a survey of the literature. Environ. Manage. 51, 251-266.

[26] L. Arata, P. Sckokai, 2016. The impact of agrienvironmental schemes on farm performance in five EU member states: a DID-matching approach. Land Econ. 92, 167-186.

[27] F. Cisilino, A. Bodini, A. Zanoli, 2019. Rural development programs' impact on environment: An ex- 
post evaluation of organic faming. Land Use Policy 85, 454-462.

[28] A. Pufahl, C.R. Weiss, 2009. Evaluating the effects of farm programmes: results from propensity score matching. Eur. Rev. Agric. Econ. 36, 79-101.

[29] M. Raggi, D. Viaggi, F. Bartolini, A. Furlan, 2015. The role of policy priorities and targeting in the spatial location of participation in Agri-Environmental Schemes in Emilia-Romagna (Italy). Land Use Policy 47, 78-89.

[30] A. Bonfiglio, A. Arzeni, A. Bodini, 2017. Assessing eco-efficiency of arable farms in rural areas. Agric. Syst. 151, 114-125.

[31] G. Breustedt, U. Latacz-Lohmann, T. Tiedemann, 2011. Organic or conventional? Optimal dairy farming technology under the EU milk quota system and organic subsidies. Food Policy 36, 223-229.

[32] T.J. Coelli, D.S.P. Rao, C.J. O’Donnell, G.E. Battese, 2005. An introduction to efficiency and productivity analysis. Springer Science \& Business Media, New York, NY.

[33] W.W. Cooper, L.M. Seiford, K. Tone, 2007. Data envelopment analysis: a comprehensive text with models, applications, references and DEA-solver software: Springer Science \& Business Media. N. Y. USA.

[34] F.A. Madau, 2007. Technical efficiency in organic and conventional farming: Evidence from Italian cereal farms. Agric. Econ. Rev. 8, 5-21.

[35] A.O. Lansink, K. Pietola, S. Bäckman, 2002. Effciency and productivity of conventional and organic farms in Finland 1994-1997. Eur. Rev. Agric. Econ. 29, 51-65.

[36] K.L. Poudel, T.G. Johnson, N. Yamamoto, S. Gautam, B. Mishra, 2015. Comparing technical efficiency of organic and conventional coffee farms in rural hill region of Nepal using data envelopment analysis (DEA) approach. Org. Agric. 5, 263-275.

[37] V. Tzouvelekas, C.J. Pantzios, C. Fotopoulos, 2001. Technical efficiency of alternative farming systems: the case of Greek organic and conventional olivegrowing farms. Food Policy 26, 549-569.

[38] E. Dimara, C.J. Pantzios, D. Skuras, K. Tsekouras, 2005. The impacts of regulated notions of quality on farm efficiency: A DEA application. Eur. J. Oper. Res. 161, 416-431.

[39] S. Alkahtani, A. Elhendy, 2012. Organic and conventional date farm efficiency estimation, and its determents at Riyadh province, Kingdom of Saudi Arabia. WIT Trans. Ecol. Environ. 162, 219-230.

[40] M. Beltrán-Esteve, E. Reig-Martínez, 2014. Comparing conventional and organic citrus grower efficiency in Spain. Agric. Syst. 129, 115-123.
[41] T. Serra, B.K. Goodwin, 2009. The efficiency of Spanish arable crop organic farms, a local maximum likelihood approach. J. Product. Anal. 31, 113-124.

[42] P. Kramol, R. Villano, P. Kristiansen, E. Fleming, 2015. Productivity differences between organic and other vegetable farming systems in northern Thailand. Renew. Agric. Food Syst. 30, 154.

[43] T. Tiedemann, U. Latacz-Lohmann, 2013. Production risk and technical efficiency in organic and conventional agriculture-the case of arable farms in Germany. J. Agric. Econ. 64, 73-96.

[44] E. Gutiérrez, E. Aguilera, S. Lozano, G.I. Guzmán, 2017. A two-stage DEA approach for quantifying and analysing the inefficiency of conventional and organic rain-fed cereals in Spain. J. Clean. Prod. 149, 335-348.

[45] S. Lakner, S. Kirchweger, D. Hoop, B. Brümmer, J. Kantelhardt, 2018. The effects of diversification activities on the technical efficiency of organic farms in Switzerland, Austria, and Southern Germany. Sustainability 10, 1304.

[46] E. Pomarici, R. Sardone, 2020. EU wine policy in the framework of the CAP: post-2020 challenges. Agric. Food Econ. 8, 1-40.

[47] G. Meloni, J.F.M. Swinnen, 2012. The Political Economy of European Wine Regulations (SSRN Scholarly Paper No. ID 2279338). Social Science Research Network, Rochester, NY.

[48] S. Green, 2018. The European Union and action on climate change, through the lens of the wine industry. Wine Econ. Policy 7, 120-127.

[49] Regulation (EU) 203/2012, 2012. Amending Regulation (EC) No 889/2008 laying down detailed rules for the implementation of Council Regulation (EC) No 834/2007, as regards detailed rules on organic wine.

[50] FIBL \& IFOAM, 2019. The World of Organic Agriculture 2019.

[51] A. Castellini, C. Mauracher, S. Troiano, 2017. An overview of the biodynamic wine sector. Int. J. Wine Res. 9, 1-11.

[52] M.A. Bonn, J.J. Cronin, M. Cho, 2016. Do Environmental Sustainable Practices of Organic Wine Suppliers Affect Consumers' Behavioral Intentions? The Moderating Role of Trust. Cornell Hosp. Q. 57, 21-37.

[53] M. D’Amico, G. Di Vita, L. Monaco, 2016. Exploring environmental consciousness and consumer preferences for organic wines without sulfites. J. Clean. Prod. 120, 64-71.

[54] C. Fotopoulos, A. Krystallis, M. Ness, 2003. Wine produced by organic grapes in Greece: using 
means-end chains analysis to reveal organic buyers' purchasing motives in comparison to the nonbuyers. Food Qual. Prefer. 14, 549-566.

[55] M. Lanfranchi, A. Zirilli, A. Alibrandi, C. Giannetto, 2020. The behaviour of wine consumers towards organic wine: a statistical analysis through the nonparametric combination test. Int. J. Wine Bus. Res.

[56] S. Mann, A. Ferjani, L. Reissig, 2012. What matters to consumers of organic wine? Br. Food J. 114, 272-284.

[57] M.M.B. Mollá-Bauzá, L. Martínez-Carrasco, A. Martínez-Poveda, M.R. Pérez, 2005. Determination of the surplus that consumers are willing to pay for an organic wine. Span. J. Agric. Res. 3, 43-51.

[58] J. Olsen, L. Thach, L. Hemphill, 2012. The impact of environmental protection and hedonistic values on organic wine purchases in the US. Int. J. Wine Bus. Res.

[59] I. Schäufele, U. Hamm, 2018. Organic wine purchase behaviour in Germany: Exploring the attitude-behaviour-gap with data from a household panel. Food Qual. Prefer. 63, 1-11.

[60] E. Pagliarini, M. Laureati, D. Gaeta, 2013. Sensory descriptors, hedonic perception and consumer's attitudes to Sangiovese red wine deriving from organically and conventionally grown grapes. Front. Psychol. 4.

[61] P. Fanasch, B. Frick, 2020. The value of signals: Do self-declaration and certification generate price premiums for organic and biodynamic wines? J. Clean. Prod. 249, 119415.

[62] L.A. Abraben, K.A. Grogan, Z. Gao, 2017. Organic price premium or penalty? A comparative market analysis of organic wines from Tuscany. Food Policy $69,154-165$.

[63] G. Ruggeri, C. Mazzocchi, S. Corsi, 2020. Drinking biodiversity: a choice experiment on Franciacorta sparkling wines. Br. Food J.

[64] K.H. Lim, M. Reed, 2020. Do ecolabels cheapen wines? J. Clean. Prod. 245, 118696.

[65] J. Aschemann-Witzel, S. Zielke, 2017. Can't buy me green? A review of consumer perceptions of and behavior toward the price of organic food. J. Consum. Aff. 51, 211-251.

[66] G. Migliore, A. Thrassou, M. Crescimanno, G. Schifani, A. Galati, 2020. Factors affecting consumer preferences for "natural wine": An exploratory study in the Italian market. Br. Food J. 122, 24632479.

[67] G. Szolnoki, K. Hauck, 2020. Analysis of German wine consumers' preferences for organic and nonorganic wines. Br. Food J.
[68] E. Pomarici, M. Amato, R. Vecchio, 2016. Environmental Friendly Wines: A Consumer Segmentation Study. Agric. Agric. Sci. Procedia, Florence "Sustainability of Well-Being International Forum". 2015: Food for Sustainability and not just food, FlorenceSWIF2015 8, 534-541.

[69] D. Moscovici, R. Rezwanul, R. Mihailescu, J. Gow, A.A. Ugaglia, L. Valenzuela, A. Rinaldi, 2020. Preferences for eco certified wines in the United States. Int. J. Wine Bus. Res.

[70] E.C. Thach, J.E. Olsen, 2006. Market segment analysis to target young adult wine drinkers. Agribus. Int. J. 22, 307-322.

[71] M.A. Delmas, L.E. Grant, 2014. Eco-labeling strategies and price-premium: the wine industry puzzle. Bus. Soc. 53, 6-44.

[72] S.E. Atkinson, C. Cornwell, 1994. Estimation of output and input technical efficiency using a flexible functional form and panel data. Int. Econ. Rev. $35,245-255$.

[73] W.H. Greene, 1980. On the estimation of a flexible frontier production model. J. Econom. 13, 101-115.

[74] C.J. Huang, J.-T. Liu, 1994. Estimation of a nonneutral stochastic frontier production function. J. Product. Anal. 5, 171-180.

[75] S.C. Kumbhakar, S. Ghosh, J.T. McGuckin, 1991. A generalized production frontier approach for estimating determinants of inefficiency in US dairy farms. J. Bus. Econ. Stat. 9, 279-286.

[76] D. Reifschneider, R. Stevenson, 1991. Systematic departures from the frontier: a framework for the analysis of firm inefficiency. Int. Econ. Rev. 32, 715-723.

[77] G.E. Battese, T.J. Coelli, 1995. A model for technical inefficiency effects in a stochastic frontier production function for panel data. Empir. Econ. 20, 325-332.

[78] T. Coelli, 1996. A Guide to Frontier Version 4.1: A Computer Program for Stochastic Frontier Production and Cost Function Estimation, Centre for Efficiency and Productivity Analysis (CEPA) Working paper 96/07, University of New, Australia. Center for Efficiency and Productivity Analysis, University of New England: Armidale, Australia.

[79] D. Knoke, G.W. Bohrnstedt, A.P. Mee, 1994. Statistics for social data analysis. Itasca, Illinois.

[80] D.A. Kodde, F.C. Palm, 1986. Wald criteria for jointly testing equality and inequality restrictions. Econom. J. Econom. Soc. 54, 1243-1248.

[81] F.A. Madau, 2011. Parametric estimation of technical and scale efficiencies in Italian citrus farming. Agric. Econ. Rev. 12, 91-111. 
[82] R.F. Townsend, J. Kirsten, N. Vink, 1998. Farm size, productivity and returns to scale in agriculture revisited: a case study of wine producers in South Africa. Agric. Econ. 19, 175-180.

[83] H. Liu, K. Lv, 2010. Productive efficiency and its influencing factors of wine-making firms in China. A research based on DEA-Tobit approach. Collect. Essays Finance Econ. 2, 1-6.

[84] V. Tzouvelekas, C.J. Pantzios, C. Fotopoulos, 2002. Measuring multiple and single factor technical efficiency in organic farming. Br. Food J. 104, 591-609.

[85] J.M. Alston, O. Sambucci, 2019. Grapes in the world economy, in: The Grape Genome. Springer, $1-24$.

[86] G. Jones, M. White, O. Cooper, K. Storchmann, 2005. Climate Change and Global Wine Quality. Climate Change, 73, 319-343.

[87] S. Petropoulos, C.S. Karavas, A.T. Balafoutis, I. Paraskevopoulos, S. Kallithraka, Y. Kotseridis, 2017. Fuzzy logic tool for wine quality classification. Comput. Electron. Agric. 142, 552-562.

[88] ISMEA, 2020. Ismea Mercati.

[89] CCIAA Bologna, 2019. Chamber of Commerce of Bologna. Commissione bio della Camera di Commercio di Bologna.

[90] F. Cisilino, L. Cesaro, 2009. Organic versus Conventional Farming: A Marketing Survey on Wine Production, in: The Crisis of Food Brands. Routledge, London, UK, 135-150.

[91] G. Sogari, C. Mora, D. Menozzi, 2016. Sustainable wine labeling: a framework for definition and consumers' perception. Agric. Agric. Sci. Procedia 8, 58-64.

[92] N. Palmieri, M. Perito, 2020. Consumers' willingness to consume sustainable and local wine in italy. Ital. J. Food Sci. 32.

[93] G. Scozzafava, F. Gerini, A. Dominici, C. Contini, L. Casini, 2018. Reach for the stars: The impact on consumer preferences of introducing a new top-tier typology into a PDO wine. Wine Econ. Policy 7, 140-152.

[94] A.M. Aldanondo-Ochoa, V.L. Casasnovas-Oliva, A. Arandia-Miura, 2014. Environmental efficiency and the impact of regulation in dryland organic vine production. Land Use Policy 36, 275-284.

[95] EU COM/2020/381 final, 2020. Communication from the commission to the European parliament, the council, the European economic and social committee and the committee of the regions. 